\title{
Ethnic disparities in neighbourhood selection: Understanding the role of income
}

\author{
Rory Coulter ${ }^{1}$ and William A.V. Clark ${ }^{2}$ \\ ${ }^{1}$ Department of Geography \\ University College London \\ Pearson Building \\ Gower Street \\ London, WC1E 6BT \\ United Kingdom \\ Email: r.coulter@ucl.ac.uk \\ 2 Department of Geography \\ University of California, Los Angeles \\ 1255 Bunche Hall \\ Los Angeles, CA 90024 \\ United States \\ Email:wclark@geog.ucla.edu
}

\section{Acknowledgements}

Rory Coulter conducted part of this research while working in the Department of Sociology at the University of Cambridge.

Understanding Society (UKHLS) is an initiative funded by the Economic and Social Research Council and various government departments, with scientific leadership by the Institute for Social and Economic Research, University of Essex, and survey delivery by NatCen Social Research and Kantar Public. The research data are distributed by the UK Data Service. The authors are solely responsible for all analyses and interpretations of the data. Census output is Crown copyright and is reproduced with the permission of the Controller of HMSO and the Queen's Printer for Scotland.

The authors would like to thank Paul Norman for very kindly supplying the deprivation data used in this research. Critical feedback from the editor and several anonymous reviewers is also gratefully acknowledged. The usual disclaimers apply. 


\section{Ethnic disparities in neighbourhood selection: Understanding the role of income}

Resurgent fears that segregation could undermine the cohesion, prosperity and security of British society require re-examining how ethnicity and economic resources interact to structure the types of neighbourhoods people relocate to when they move. This paper uses the United Kingdom Household Longitudinal Study and 2011 census data to assess how ethnicity and income intersect to stratify the ethnic and socio-economic composition of the neighbourhoods people move to in England and Wales. The results suggest that greater access to resources allows people from most ethnic groups to act on shared residential preferences by moving to more advantaged locales. Furthermore, higher incomes accelerate ethnic de-concentration by carrying Asians into neighbourhoods with a greater share of White Britons. However, there is also considerable inertia and ethnic inequality in neighbourhood destinations. The geography of local opportunity structures constrains the types of neighbourhood people relocate to and ethnic minorities tend to move to less advantaged neighbourhoods than their White British peers. Although Britain is not 'sleepwalking to segregation', there are persistent ethnic and socio-economic disparities in neighbourhood outcomes.

Keywords: ethnicity; income; neighbourhoods; residential mobility; segregation 


\section{Introduction}

Polarised immigration debates, urban disturbances such as the 2011 riots in English cities and recent terrorist atrocities have all revived anxiety about the connections between segregation, the nature of British citizenship and national security (Sturgis et al., 2014). These concerns have led policymakers to identify the residential clustering of ethnic minorities (especially South Asian Muslims) in often deprived areas as a threat to social integration, community cohesion and ultimately national identity (Cameron, 2015; Phillips, 2006). In 2016, the wide-ranging Casey Review into Opportunity and Integration suggested that a host of social ills - including mutual mistrust, extremism, prejudice, inequality and limited social mobility - are all exacerbated when people live in divided communities where they do not interact with individuals from different backgrounds. To tackle these issues, urban policymakers in Britain and elsewhere have espoused a commitment to combat residential segregation by creating more 'mixed communities' (see Imbroscio, 2012).

In Britain, political interpretations of ethnic residential patterns have tended to emphasize minorities' self-segregating choices rather than other demographic dynamics or the unequal constraints that limited resources, racialized space perceptions and unequal housing markets can impose on residential decision-making (Phillips and Harrison, 2010; Robinson, 2005; Simpson, 2007). Yet the popular narrative that Britain is 'sleepwalking' towards pernicious levels of segregation where people from different backgrounds lead 'parallel lives' has been extensively challenged (Finney and Simpson, 2009; Peach, 2009; 
Poulsen et al., 2011). Census data show that ethnic diversity is increasing in many locales as minorities decentralize from metropolitan gateways to non-traditional locations (Catney, 2016a; 2016b; Peach, 2009; Rees and Butt, 2004). Furthermore, survey analysis indicates that neither the ethnic composition of neighbourhoods nor proxy measures of White Flight or ethnic avoidance have a major impact on moving desires or behaviour (Clark and Coulter, 2015; Kaufmann and Harris, 2015). For recent generations raised in diverse contexts ethnic segregation may actually reduce perceptions of local social cohesion (Sturgis et al., 2014). Clearly the often alarmist public debate needs to be a lot more nuanced and tied to these complex empirical findings (Cantle and Kaufmann, 2016; Johnston et al., 2010; Peach, 2009).

The limited evidence for self-segregation means that academic explanations of ethnic residential mobility patterns have tended to stress the importance of economic resources (Catney and Simpson, 2010). Many authors argue that access to resources allows people to act on shared underlying residential preferences (Clark et al., 2014; Finney et al., 2015). The basic idea is that both ethnic minorities and White Britons usually have a commonplace wish to live in spacious dwellings in desirable neighbourhoods with access to amenities such as good schools and high quality services. Economically successful minorities are able to use their resources to obtain these valued residential attributes by moving out of settlement city centres to more suburban or rural environments which happen to have a higher proportion of White British residents (Catney and Simpson, 2010; Rees and Butt, 2004). Rather than White Flight from ethnically concentrated neighbourhoods, the trend is thus for affluent individuals from all backgrounds to leave 
densely populated places in order to fulfil common housing preferences (Finney et al., 2015; Simpson and Finney, 2009). In this view ethnic penalties in the labour market are a key reason why some minority groups - particularly Bangladeshis and Pakistanis - are disproportionately concentrated in deprived urban neighbourhoods (Jivraj and Khan, 2015; Simpson et al., 2009).

A second literature argues that some ethnic groups may also use their resources differently when moving neighbourhoods. On one hand, affluent minorities may opt to cluster in 'ethnic enclaves' in order to maintain social and kin networks or to obtain the communal benefits (for example access to specialist services or cultural facilities) that can be gained through residential clustering (Johnston et al., 2002; Peach, 1996). At the same time, US theories of place stratification suggest that some minorities might find it harder than the majority population to convert their resources into valued neighbourhood attributes, for example if racial barriers in the labour or housing markets constrain moving decisions (Pais et al., 2012). In Britain, intangible obstacles such as racialized space perceptions and fears of harassment are thought to indirectly constrain minorities' moving decisions and help to create protective patterns of residential clustering (Robinson, 2005).

In light of these politicised debates about how choices and constraints influence ethnic residential dynamics, this study asks how do ethnicity and income influence the neighbourhood outcomes of residential moves in England and Wales? We measure neighbourhoods using small 2011 census zones and define neighbourhood outcomes in terms of the ethnic composition (specifically the percentage of White Britons) and 
deprivation level of the locales people relocate to when they move. The paper extends existing research in three key ways. First, we use rich panel data to examine a specific economic mechanism that influences neighbourhood destinations and thus the mobility processes underlying neighbourhood dynamics. It is not possible to do this with the crosssectional census data used by much previous work as the UK census does not ask

questions about income. Second, we use interaction effects to assess whether the residential effects of income vary by ethnicity. Third, we go beyond the prevailing focus on ethnic segregation to consider how the socio-economic status of destination neighbourhoods also varies with income and ethnicity. This is important as previous research posits that living or growing up in deprived neighbourhoods can have lasting adverse implications for life outcomes (Hedman et al., 2011).

\section{Ethnicity, income and neighbourhood selection}

Life course models of residential mobility posit that many people move in order to adjust their dwelling and location to meet their changing needs and preferences (Clark and Ledwith, 2006). In this framework volitional moving decisions are often conceptualized as a two-step process that begins with the formation and expression of a desire or preference to move (Brown and Moore, 1970; Coulter et al., 2011). If moving seems viable people then conduct a search, evaluate accessible options and finally select a dwelling and neighbourhood that fulfils their desiderata (Brown and Moore, 1970). 
This process of residential selection is bounded in two ways. On one hand, choices about residential neighbourhoods are conditioned by the uneven geography of the dwelling stock. As certain types of housing are disproportionately located in certain types of neighbourhood (for example owner-occupied detached homes in suburban or rural areas), dwelling preferences and housing stock geography often restrict the neighbourhood choice sets facing people with different levels of resources (loannides and Zabel 2008).

On the other hand, resource constraints also structure whether people can act on their residential preferences by moving to neighbourhoods they want to live in (Bailey, 2012). Many studies show that people with greater access to resources are able to act on a preference to live in desirable dwellings and advantaged neighbourhoods, while limited purchasing power channels the poor into less advantaged areas with cheaper housing (Bailey and Livingston, 2007; Clark and Ledwith, 2007; Clark and Morrison, 2012; Hedman et al., 2011). The resulting socio-economic sorting has a strong ethnic dimension in places like the US where the weaker economic position of minorities and recent immigrants is compounded by racial barriers in the housing system (Crowder et al., 2012; Pais et al., 2012; South et al., 2008). However unlike ethnic segregation, the processes producing socio-economically stratified neighbourhoods are often treated as a taken-forgranted and 'natural' aspect of urban dynamics in market economies (Phillips, 2006).

By contrast, debates about neighbourhood change frequently cast the residential behaviour of different ethnic groups as a potential problem for public policies aiming to 
reduce inequality and crime, promote social cohesion and enhance national security (Poulsen et al., 2011). A recurring question has been the extent to which ethnic moving patterns reflect divergent neighbourhood preferences rather than the ways in which minorities' moving decisions are unequally bounded by constraints such as limited resources, housing tenure disparities, (fears of) discrimination or racialized neighbourhood perceptions (Clark and Ledwith, 2007; Phillips and Harrison, 2010; Robinson, 2005). Crucially, these explanations may be complementary and their relative importance may vary across time, space and societies (Pais et al., 2012). This means that US theories developed to explain the persistent residential disadvantage of African Americans cannot be uncritically applied to European societies with different dynamics of diversity and different patterns of ethnic inequality (Johnston et al, 2010; Peach, 2009).

The idea that differential access to resources might be an important reason for ethnic patterns of residential settlement and neighbourhood transition was first posited by Chicago School theories of spatial assimilation (Finney et al., 2015). The basic idea is that as immigrants become established and minorities improve their socio-economic position they become increasingly able to act on the preferences for improved residential conditions they come to share with the majority population (Clark and Ledwith, 2007; Simpson and Finney, 2009). This leads to declining ethnic segregation as minorities move away from areas of cheap rental housing in immigrant gateways to more prosperous and advantaged areas traditionally dominated by the native majority. Importantly, Finney and colleagues (2015) caution that this ethnic de-concentration should not be equated with 
socio-cultural assimilation as minorities may retain distinctive practices and have a strong sense of independent identity.

British analyses largely support the main predictions of this framework (Cantle and Kaufmann, 2016). Census data show that ethnic segregation is falling as minorities disperse and mix residentially with White Britons in non-traditional locales (Catney 2016a; 2016b; Peach, 2009; Rees and Butt, 2004). Although this may be partly due to patterns of immigration and natural increase (Rees et al., 2013), Rees and Butt (2004: 185) observed that socially selective mobility became important between 1991 and 2001 as advantaged ethnic minority households joined "the general population pattern of suburbanization and metropolitan deconcentration". This conclusion that economic resources enable minorities to act on the residential preferences they share with the majority population is echoed by Catney and Simpson (2010), who argue that market-led explanations of residential sorting largely explain minority movement out of gateway locations. This argument implies that the persistence of ethnic geographies and the overrepresentation of some minority groups in deprived urban areas is heavily due to ethnic disadvantage and ethnic penalties in the labour market (Simpson et al., 2009). Housing barriers such as difficulty moving long distances within the social rental system as well as perceptions of harassment, discrimination and racialized space may also restrict minorities' ability and inclination to exit deprived ethnically concentrated urban neighbourhoods (Finney et al., 2015; Phillips, 2006; Robinson, 2005). 
If these resource-led explanations of neighbourhood selection are broadly correct, then we would expect to find that higher household incomes enable people to move to less deprived neighbourhoods regardless of their ethnicity. By contrast, the links between income, ethnicity and the share of minorities in destination neighbourhoods are likely to be more ambiguous than in the US because European geographies of deprivation tend to be more weakly associated with the geography of ethnicity (Bailey, 2012). However, it is likely that differences in local opportunity structures mean that the ethnic composition of neighbourhood destinations will vary by individual ethnicity (Kaufmann and Harris, 2015). Local opportunity structures are likely to influence patterns of neighbourhood outcomes because ethnic minorities are not evenly distributed across the country (Finney et al., 2015), most people move short distances (Stillwell and Thomas, 2016) and neighbourhoods frequently have similar characteristics to those around them. This spatial patterning of choice sets may be especially relevant for minorities as some groups are less likely than White Britons to migrate over long distances (Finney et al., 2015).

A second set of perspectives suggest that the ways people use income in neighbourhood transitions might also vary by ethnicity. On one hand this could be due to ethnic differences in residential priorities and preferences. Many studies have drawn variously on Chicago School ecological 'invasion-succession' metaphors of neighbourhood change, ideas of White Flight and Schelling's (1971) models of residential sorting to argue that small intergroup differences in preferences for majority and minority neighbours can have large effects on aggregate patterns of neighbourhood selection (Clark, 2008). A key aim of this literature has been unpacking the relative importance of preferences to avoid 
or live with neighbours of particular ethnicities, as well as the extent to which people eschew neighbourhoods with a large share of minorities because this is a proxy for deprivation (van Ham and Feijten, 2008). In contrast to discourses of White Flight and self-segregation, much of this literature argues that ethnic clustering is not inimical to social integration and may in fact help minorities to maintain social and kin networks, access specific services or facilities and exchange information or support (Johnston et al., 2002; Peach, 1996; Robinson, 2005).

Although British research reports little evidence for large-scale White Flight or ethnic avoidance (Cantle and Kaufmann, 2016; Kaufmann and Harris, 2015; Simpson and Finney, 2009), the persistence of prosperous ethnic enclaves and the important role that social networks and place attachments play in moving decisions suggest that it is unlikely that the ethnic composition of neighbourhoods carries no weight in moving decisions (Clark and Coulter, 2015; Finney et al., 2015; loannides and Zabel, 2008). Moreover, qualitative work by Phillips (2006) suggests that racialized perceptions of space and threat may exert complex effects on the moving behaviour of the majority and minority residents of some British cities (Robinson, 2005). On one hand this evidence implies that we might expect income to have relatively little impact on the ethnic composition of neighbourhood destinations. On the other hand, the reality may be somewhat more ambiguous if economically successful minorities also seek better residential conditions by moving out of city centres to less deprived neighbourhoods which happen to typically have a higher share of White British residents. 
Theories of place stratification devised in the racialized US housing system indicate that in this context ethnic minorities also face disproportionate constraints in converting their income into neighbourhood attainments (Crowder et al., 2012; Pais et al., 2012; South et al., 2008). Work by Pais et al. (2012) shows that the social and spatial mobility of ethnic minorities is inhibited in urban America by the greater difficulty they face in using their income to access prosperous White neighbourhoods (South et al., 2008). Although the history and geographies of ethnic settlement, disadvantage and discrimination are very different in Britain, if place stratification has any relevance here we would broadly expect to find significant ethnic disparities in neighbourhood outcomes after controlling for differences in local opportunity structures. We would particularly expect to find evidence that minorities are less able than their White British counterparts to use higher incomes to access socio-economically advantaged neighbourhoods.

\section{Research approach}

\section{Data and sample}

This study uses the first six waves of the United Kingdom Household Longitudinal Study (UKHLS). UKHLS is a nationally representative panel survey that began in 2009 when over 50,000 adults aged 16 and older in 30,000 households completed wide ranging faceto-face interviews (Knies, 2017). Participants are interviewed every year although each wave of data collection spans twenty-four calendar months. 
UKHLS is a complex survey with several components. In addition to the main General Population Sample the study includes an Ethnic Minority Boost designed to yield at least 1,000 adults from five specific minority groups: Indian, Pakistani, Bangladeshi, Caribbean and African (Knies, 2017). Former members of the British Household Panel Survey (BHPS) were incorporated into UKHLS in wave two. To avoid the risk of introducing accumulated selection biases into our sample we do not draw on BHPS respondents. As there are differences in the census micro-geographies in use across the United Kingdom we further restricted our sample to respondents living in England and Wales.

We began by adapting the Office for National Statistics (ONS) system of ethnic classification to code the sample into six ethnic groups (ONS, 2012a): (1) White British; (2) Other White (Irish, Gypsy//rish Traveller, Other White); (3) Mixed/Multiple ethnicity; (4) Asian (Indian, Pakistani, Bangladeshi, Chinese, Other Asian); (5) Black (African, Caribbean, Other Black) and (6) Other (Arab, Other ethnicities). The advantage of using this broad classification system is that it fits with census outputs, has some public currency and provides a sufficient number of residential moves within each ethnic group to support regression models of neighbourhood transitions. However, it is very important to recognise the limitations of our categorisation schema. Ethnicity is a complex sociocultural construct and our coding obscures significant within-group variation in national heritage (for example the Other White group pools Europeans with North American/Commonwealth citizens), religion (for instance the Asian category includes Indian Hindus as well as both Indian and Pakistani Muslims) and migration dynamics (for 
example in terms of arrival dates and settlement patterns). As UKHLS matures it will hopefully capture sufficient residential moves to support more nuanced research into the neighbourhood outcomes of a diverse range of ethnic, cultural and religious subgroups.

For this paper we restrict the sample to White British, Other White, Asian and Black respondents as the remaining categories are particularly heterogeneous and comprised only $3.2 \%$ of the population at the time of the 2011 census (ONS, 2012a: 3 ). We then selected respondents who were either interviewed in all waves of UKHLS or who had always completed a full interview since maturing into the adult panel. This restriction allows us to use the longitudinal response weights to correct for unequal selection probabilities, differential nonresponse, sampling error and selective attrition (Knies, 2017). The latter process could be important for this study as people are often particularly prone to disappear from longitudinal surveys when they move house.

One eligible respondent per household was then randomly selected at baseline and tracked. This procedure ensures that we do not include multiple cases from households where several individuals make a joint move. After removing a handful of cases with missing data on key variables the final sample comprised 58231 person-years provided by 11753 individuals (mean=4.95 records per person).

Neighbourhood data from the 2011 census were then added to the UKHLS person-year file using the survey geocodes. Although it is well-known that neighbourhoods are not objective entities and that the way they are defined can affect results, we use Lower Layer 
Super Output Areas (LSOAs) as a pragmatic approximation of neighbourhoods (Clark and Coulter, 2015; Jivraj and Khan, 2015; Rabe and Taylor, 2010 for prior examples). LSOAs are aggregations of census Output Areas that are designed to contain 1500 individuals (acceptable range $=1000-3000$ ) and 600 households (acceptable range $=400$ 1200 ) in an area that is compact and relatively socially homogenous (ONS, 2012b). There were 34753 LSOAs in England and Wales in 2011 and given our research question we defined residential moves as an LSOA change between waves $t-1$ and $t$ (cf. Pais et al., 2012). Using this definition yields an annual mobility rate of roughly $7 \%$, which is several percentage points lower than estimates derived from the 2011 census (Stillwell and Thomas, 2016). Although this suggests that UKHLS may be under-enumerating residential moves, our rate is probably also on the low side because we do not consider intra-LSOA moves or multiple moves from the same origin household. We treat each LSOA transition as an independent event as nearly $75 \%$ of movers were observed to relocate only once (mean $=1.3$ times).

\section{Measures and methods}

The dependent variables measure two attributes of destination LSOAs using data collected by the 2011 census. The first indicator is the percentage of White British usual residents. Across all LSOAs this ranges from $0.7 \%$ in a West Yorkshire LSOA with a large Asian population through to $99.7 \%$ in a former industrial district of the North East (mean=81.4\%). The second dependent variable is the LSOA Carstairs deprivation score. The Carstairs Index is a well-known measure of deprivation derived using 2011 census 
data on the LSOA male unemployment rate, percentage of households without car access, percentage of overcrowded households and percentage of persons with a lower occupational class (Norman et al., 2005). Each of these variables is standardised in relation to national levels using z-scores and these scores are then summed to yield an overall index where 0 indicates the national average. Higher positive values signify more deprived LSOAs. Across England and Wales the distribution of LSOA scores stretches from -5.6 to +13.4 . We use the Carstairs Index rather than the Indices of Multiple Deprivation (IMDs) used within government and by some prior research because the English and Welsh IMDs are computed slightly differently (Jivraj and Khan, 2015).

Our key independent variable is income in the wave prior to a move. As our panel is too short to derive a rolling smoothed measure of average incomes we define income pragmatically as total gross monthly household income expressed in 2015 values and equivalized using the Modified OECD scale. To reduce skewness this variable is log transformed. As incomes are only one aspect of resource access we also control for lagged employment status and educational qualifications in the modelling work. In addition, we include lagged control variables to capture a range of other personal and household attributes (Tables 1 and 2 for full details) which numerous studies have indicated shape mobility decision-making and outcomes (Clark et al., 2014; Coulter et al., 2011).

As Stillwell and Thomas (2016) show that most moves within England are relatively short distance (also Bailey and Livingston, 2007), we control for differences in the ethnic 
geography of local opportunity structures with a variable recording the percentage of White Britons in the origin Local Authority District (henceforth district, local government areas with a median 2011 population of 126,000$)$. To capture the socio-economic opportunity structure of neighbourhoods a second variable measures the proportion of the origin district LSOAs that fall into the most deprived national quintile. As districts are administrative units that vary in size and population composition, we have also rerun our analyses using similar control variables defined at the coarser scale of functional Housing Market Areas (Coombes and Wymer, 2010). The results were very similar and are not shown.

Another control is included to distinguish moves between and within districts because longer distance migrants are a selective group of more advantaged individuals who might be disproportionately able to access desirable neighbourhoods. We also use LSOA and district level indicators of population density in the descriptive analysis to explore how people move across the settlement hierarchy. These variables are discarded from the regressions to avoid multicollinearity and because they contributed little to model fit. Similar considerations led us to exclude a measure of residential crowding as well as polynomial terms for continuous predictors.

The analysis begins by comparing the neighbourhood origins and outcomes of movers of different ethnicities. We then estimate simple linear regression models where the dependent variable is first the percentage of White Britons and second the Carstairs score of destination LSOAs. Both models interact ethnicity with income to test whether all ethnic 
groups tend to move to more White British and less deprived neighbourhoods when they have higher incomes. As the UK census does not ask questions about income this approach allows us to extend census analyses by examining a specific channel through which ethnicity and resource access may intersect to influence the neighbourhood outcomes of residential moves.

All continuous predictors are centred on their grand means. Ideally we would test for spatial patterns in the ethnicity-income relationship by extending the models to include district level random intercept, cross-level interaction and possibly random slope terms (Pais et al., 2012). However, the relatively low number of moves we observe when the sample is broken down by ethnicity means that we leave this for further research using larger datasets. All models fit well and produce predictions which are plausible and with a sensible distribution in relation to observed values. After interpreting the models, we plot adjusted predictions for a hypothetical sample member by varying their ethnicity and income when all control variables are set to mean or reference category values.

\section{Results}

Descriptive analysis

Tables 1 and 2 contextualise the main analysis of neighbourhood outcomes by comparing the characteristics of person-years where the individual subsequently moved (Table 2) with cases where no move took place (Table 1). These tables disaggregate stayers and 
movers by ethnicity in order to provide a richer picture of ethnic differences in attributes and residential mobility behaviour.

Comparing Tables 1 and 2 shows that in all ethnic groups movers are on average younger than stayers (especially among White Britons). In line with well-documented patterns, White British movers are more often single or cohabiting than their staying counterparts (Other White movers are also more likely than Other White stayers to be cohabiting). By contrast, very few Asians cohabit and a particularly large share of Asian movers are married. The partnership status of Black movers is very similar to Black stayers and a large share of moving Blacks have young co-resident children.

On average movers are disproportionately likely to have higher qualifications and be either employed or in education before relocating. However, these aggregate patterns mask considerable ethnic variations. Although White British and Asian movers are much more likely than their staying counterparts to have higher qualifications, these educational gradients are not observed for Other White or Black movers. A relatively high proportion of Black movers are students, while movers from all other ethnic groups are more likely than stayers to be employed. In general, mean household incomes are similar or slightly higher amongst movers, probably due to their higher educational qualifications and greater participation in paid work. Overall Asian and Black respondents report considerably lower equivalised household incomes than White Britons and Other Whites. This reflects persistent ethnic disparities in labour markets (Simpson et al., 2009). 
Tables 1 and 2 show that White Britons and Asians are relatively advantaged in the housing system as they have a much higher homeownership rate than either of the other ethnic minority groups. By contrast, Blacks are disproportionately likely to live in social housing. Across all ethnic groups a large share of movers are private tenants, while homeowners and to a lesser extent social tenants are over-represented among stayers. Around $38 \%$ of observed moves cross district boundaries. Encouragingly this figure corresponds closely with estimates derived from the 2011 census (40\%) and a large commercial dataset (34\%) by Stillwell and Thomas (2016: 28, 37).

${ }^{* * *}$ Table 1 about here ***

The lower panels of Table 2 show the characteristics of the LSOAs and districts that movers lived in at $t-1$ (prior to moving) and $t$ (after relocation). In general, all groups tend on average to live in areas with a slightly greater proportion of White Britons after moving, although minority movers (particularly Asians) originate in much more ethnically concentrated areas than White Britons. On the one hand this means that residential mobility redistributes ethnic minorities to more White British areas and thus tempers the residential separation between majority and minority ethnic groups (Cantle and Kaufmann, 2016). However, on the other hand, the fact that ethnic minorities still tend to live in much less White British areas after relocating suggests that this is a relatively gradual process. 
Table 2 shows that ethnic minorities - especially Asians and Blacks - tend to live in more deprived parts of England and Wales than native White Britons (Jivraj and Khan, 2015). However, in line with notions that people from all backgrounds frequently 'move to improve' (Clark et al., 2014), movers of all ethnicities on average live in considerably less deprived LSOAs and districts after relocating. At both the neighbourhood and district scale all movers tend on average to also be living in less densely populated areas after relocation. At the aggregate level residential mobility therefore tends to propel individuals outwards from urban centres, probably in search of better housing and neighbourhood conditions.

Overall Table 2 shows that despite stark ethnic disparities in neighbourhood origins and outcomes, the average direction of neighbourhood change that occurs with residential mobility does not vary substantially by ethnicity. In line with theories of spatial assimilation and life course change, residential mobility on average leads movers to relocate to less densely populated and more socio-economically advantaged neighbourhoods with a higher proportion of White Britons. However, the neighbourhood matrix is also rather 'sticky' as residential mobility has only a fairly minor impact on the locational attributes of individuals from all ethnicities.

\section{Modelling neighbourhood outcomes}

Table 3 presents two linear regression models where the dependent variable is the percentage of White Britons (Model 1) or the Carstairs score (Model 2) of the destination 
LSOA, conditional on making a residential move. The control variable effects in Model 1 are largely consistent with life course explanations of neighbourhood choice that emphasize the importance of preferences, resources and opportunities. Movers who are older, married or living with children tend to relocate to more White British neighbourhoods than their younger, single and childless counterparts. This is probably because preferences for larger dwellings and a more child-friendly environment in the family formation life phase motivate moves to less densely populated places. For historic reasons these locations also happen to have fewer ethnic minorities. The origin local opportunity structure also strongly affects the ethnic concentration of destination LSOAs. Those originating in districts where a large share of the population are White British or where more people live in deprived areas are more likely to end up in White British neighbourhoods than individuals originating in areas with a large minority population or less deprived profile of neighbourhoods.

The main parameters of interest in Model 1 show that at the mean level of income ethnic minorities - most notably Asians and least notably Other Whites - tend to move to LSOAs with a significantly lower proportion of White Britons than their White British peers. Table 2 indicates that this is partly likely to be because most people move short distances (Stillwell and Thomas, 2016) and ethnic minorities tend to originate in locales with a substantially greater share of ethnic minority residents. For White Britons there is little evidence for ethnic avoidance by the affluent as lagged household income has no significant link to the ethnic outcomes of residential moves. By contrast, there are strong but imprecisely estimated (i.e. with wide confidence intervals) positive income interaction 
effects for Other Whites and especially Asians (the latter attains significance at the $5 \%$ threshold). This indicates that higher incomes are particularly associated with moving to more White British areas for these groups. This is consistent with Catney and Simpson's (2010) argument that access to resources is a key factor enabling the de-concentration and suburbanization of ethnic minorities to areas with a large White British population. The very wide confidence intervals surrounding the interaction effect for Blacks suggests that this group do not differ from White Britons in terms of how they use income to move between neighbourhoods with differing shares of White British residents.

*** Table 3 and Figure 1 about here ***

Figure 1 uses the estimates in Model 1 to plot the predicted percentage of White Britons in the destination LSOA by income (transformed to pounds) and ethnicity for a hypothetical mover with average or reference category characteristics. For both White Britons and Blacks there is no obvious income gradient in the ethnic composition of destination neighbourhoods, although Blacks do tend to move to neighbourhoods with fewer White Britons than their White British peers. By contrast, Asian and to a much lesser extent Other White movers become somewhat more likely to move to more White British LSOAs as household income increases. The positive effect of income is especially pronounced for poorer Asians and at the upper end of the income distribution there is only a weak effect of individual ethnicity on the ethnic composition of destination neighbourhoods. This provides further support for resource-led explanations of neighbourhood selection, as well as evidence that moving does not eliminate the 
tendency for Asian and Black minorities to reside in more ethnic LSOAs than White Britons.

Model 2 in Table 3 repeats the analysis but switches the dependent variable to the Carstairs score of the destination LSOA. The control variable effects again demonstrate how life course position as well as resources and opportunities strongly shape neighbourhood outcomes. Younger individuals and singles tend to move to more socioeconomically disadvantaged neighbourhoods than those who are older or married. Low levels of education, disengagement from paid work or study and especially social tenancies channel movers with a weaker socio-economic position and more limited housing options into more disadvantaged neighbourhoods. Evidence that longer distance movers tend to relocate to less deprived neighbourhoods confirms that migrants are a socially selective group with greater access to resources. Unsurprisingly, people tend to move to more disadvantaged LSOAs when coming from districts where a greater share of residents live in deprived areas.

Even after taking into account income and local opportunity structures, Model 2 shows that ethnic minorities - especially Asians and Blacks - tend to move to more disadvantaged neighbourhoods than White Britons. Unsurprisingly, amongst White Britons higher incomes are associated with moving to less deprived LSOAs. The insignificant interaction effects for all but Other Whites indicate that the slope of the income effect is fairly similar for most ethnic groups. Intriguingly, the positive interaction term for Other Whites indicates that members of this group become increasingly likely to 
move to more deprived LSOAs as income rises. Taken together these results suggest that ethnic minority groups generally use higher incomes to escape deprived areas in a broadly similar fashion to White Britons, although the Other White result requires further consideration.

*** Figure 2 about here ***

Figure 2 replicates Figure 1 using the estimates from Model 2. In line with theories that emphasize the connections between social and spatial mobility, the deprivation outcomes of White Britons, Asians and Blacks converge as income increases and all groups tend to move to less deprived neighbourhoods. However, this pattern does not eliminate persistent ethnic inequalities as across the income distribution Asians tend to move to less advantaged LSOAs than their White British peers. The main exception to the general pattern of higher incomes translating into moves to less deprived LSOAs is provided by Other Whites. This inconsistency hints that migrant origins and settlement history might also shape the residential preferences of ethnic minorities with greater access to resources.

Overall, the shape of the income effects do not support strong notions of place stratification. Despite facing persistent disadvantages, greater affluence does in general enable Asian and Black minorities to move to more prosperous neighbourhoods in England and Wales. Higher incomes also increase the tendency for Asians to move to more White British neighbourhoods. This suggests that the neighbourhood outcomes of 
residential mobility are stratified by ethnicity largely because of unequal access to income and the uneven geography of where people are living before they move.

\section{Conclusion and discussion}

In recent years British debates about social cohesion, national security and citizenship have linked a host of social problems to ethnic segregation and an assumed tendency for minorities to choose to cluster together in deprived urban neighbourhoods (Casey Review, 2016; Peach, 2009; Poulsen et al., 2011). Yet these beliefs rest on a shaky understanding of ethnic patterns of residential mobility, and especially the role played by differential access to economic resources (Cantle and Kaufmann, 2016). In general research finds little support for the notion that Britain is becoming more segregated and divided along ethnic lines as minorities choose to cluster together and disengage from wider society (Catney, 2016b; Peach, 2009; Phillips, 2006). Rather than 'sleepwalking to segregation', prior analyses of population mobility suggest that shared preferences to live in better dwellings in more advantaged neighbourhoods are often a more potent factor in moving decisions than preferences to avoid or live alongside neighbours from particular ethnic groups (Catney and Simpson, 2010; Finney and Simpson, 2009). In view of these complex debates and the persistence of ethnic inequalities (Simpson et al., 2009), this paper used rich panel survey data to take a fresh look at how ethnicity and income interact to shape the types of neighbourhoods people relocate to when they move. 
We find little evidence to support US theories positing that ethnic groups use income in markedly different ways when moving to a new neighbourhood. For White Britons, Asians and Blacks higher incomes translate into a shared tendency to relocate to more socioadvantaged neighbourhoods. This suggests that resources allow people from a range of backgrounds - although interestingly potentially not Other Whites - to 'move to improve' by acting on common housing and neighbourhood preferences. Further work is now needed to disaggregate the broad ethnic categories used in this study to explore the interacting effects of ethnicity, nativity and housing market factors on neighbourhood transitions. In particular, this could help to unpack the somewhat divergent patterns for Other Whites that we have observed.

A second conclusion is that income plays a weaker and less clear-cut role in sorting people into neighbourhoods with different ethnic profiles. The insignificant income effects for White Britons validate existing research by providing little evidence that economically advantaged members of the native majority avoid ethnic minorities when they move. However, for Asians the tendency to move to more White British neighbourhoods increases with income. This is most likely to be a side effect of social mobility, as historic patterns of immigrant settlement mean that moving to a less deprived and less urbanized area will often also carry minorities to a place with a larger share of White British residents. Overall, the results broadly support Catney's (2016b: 1706) proposition that Britain is gradually "sleepwalking into de-segregation" as many minorities use their resources to move to slightly more advantaged and more White British locales. 
However, we must not let this evidence of socio-spatial fluidity overshadow lingering patterns of restriction and constraint. As most people move over relatively short distances, it is perhaps unsurprising that opportunity structures in origin districts are very potent predictors of neighbourhood outcomes. To a large extent where you end up in the neighbourhood matrix is shaped by where you start out - disadvantaging minority movers. At the individual level preferences linked to life stage as well as more 'permanent' markers of resource access such as educational qualifications or housing tenure also configure neighbourhood selection. Ethnic differences in life course trajectories as well as incomes will therefore have a large cumulative impact on aggregate disparities in neighbourhood outcomes.

Finally, even after controlling for a range of other factors the neighbourhood mosaic remains rather 'sticky', as there are still significant ethnic inequalities in the neighbourhood outcomes of residential moves. Ceteris paribus ethnic minorities tend to relocate to less advantaged neighbourhoods and neighbourhoods with a greater share of minorities than their White British peers. Further work is needed to disentangle the extent to which these patterns are due to choices and trade-offs concerning networks and desirable neighbourhood attributes, as opposed to the various ties and constraints that can bound mobility decisions. As British politicians have consistently expressed concern about the segregation of South Asian Muslims (Phillips, 2006), future studies particularly need to explore the extent to which religious differences and perhaps a desire to live near to religious facilities may underlie ethnic differences in mobility patterns. 
This study also suggests several broader avenues for future geographical research. First, it would be fruitful to more thoroughly test the predictions of spatial assimilation and place stratification theories by using larger samples and multilevel models to investigate whether nativity, ethnicity and income shape the neighbourhood outcomes of residential moves in different ways in different parts of the country (Pais et al., 2012). Such work could also examine whether our results have been influenced by period effects linked to the Global Economic Crisis, or recent policy interventions such as reforms to the welfare and social housing systems. Second, longitudinal analysis of life events could yield new insights about how biographical processes channel people from different ethnicities into different sorts of neighbourhood (Rabe and Taylor, 2010). As the UKHLS panel lengthens this could involve using dynamic models to examine how changes in income or other socio-economic resources are associated with transitions in neighbourhood characteristics. Finally, developing holistic dependent variables which combine neighbourhood deprivation, ethnic composition and finely grained person-place ethnic or religious 'matching' may allow us to more comprehensively disentangle how choices and constraints shape ethnic geographies of neighbourhood destinations. 


\section{References}

Bailey, N. and M. Livingston (2007) Population Turnover and Area Deprivation. The Policy Press, Bristol.

Bailey, N. (2012) How spatial segregation changes over time: Sorting out the sorting processes. Environment and Planning A 44.3, 705-722.

Brown, L.A. and E.G. Moore (1970) The intra-urban migration process: A perspective. Geografiska Annaler, Series B 52.1, 1-13.

Cameron, D. (2015) Extremism: PM speech. 20 th July. [WWW document]. URL https://www.gov.uk/government/speeches/extremism-pm-speech (accessed 09 April 2018).

Cantle, T and E. Kaufmann (2016) Is segregation increasing in the UK? $2^{\text {nd }}$ November. [WWW document]. URL https://www.opendemocracy.net/wfd/ted-cantle-and-erickaufmann/is-segregation-on-increase-in-uk (accessed 09 April 2018).

Casey Review (2016) The Casey Review: A review into opportunity and integration. Department for Communities and Local Government: London. URL https://www.gov.uk/government/publications/the-casey-review-a-review-intoopportunity-and-integration (accessed 09 April 2018). 
Catney, G. (2016a) The changing geographies of ethnic diversity in England and Wales, 1991-2011. Population, Space and Place 22.8, 750-765.

Catney, G. (2016b) Exploring a decade of small area ethnic (de-)segregation in England and Wales. Urban Studies 53.8, 1691-1709.

Catney, G. and L. Simpson (2010) Settlement area migration in England and Wales: Assessing evidence for a social gradient. Transactions of the Institute of British Geographers 35.4, 571-584.

Clark, W.A.V. (2008) Geography, space, and science: Perspectives from studies of migration and geographical sorting. Geographical Analysis 40.3, 258-275.

Clark, W.A.V. and R. Coulter (2015) Who wants to move? The role of neighbourhood change. Environment and Planning A 47.12, 2683-2709.

Clark, W.A.V. and V. Ledwith (2006) Mobility, housing stress and neighborhood contexts: Evidence from Los Angeles. Environment and Planning A 38.6, 1077-1093.

Clark, W.A.V. and V. Ledwith (2007) How much does income matter in neighborhood choice? Population Research and Policy Review 26.2, 145-161. 
Clark, W.A.V. and P. Morrison (2012) Socio-spatial mobility and residential sorting: Evidence from a large scale survey. Urban Studies 49.15, 3253-3270.

Clark, W.A.V., M. van Ham and R. Coulter (2014) Spatial mobility and social outcomes. Journal of Housing and the Built Environment 29.4, 699-727.

Coombes M. and C. Wymer (2010) Geography of Housing Market Areas (HMAs) in England: Stage 2 Report from CURDS. [WWW document]. URL www.ncl.ac.uk/media/wwwnclacuk/curds/files/3.pdf (accessed 09 April 2018).

Coulter, R., M. van Ham and P. Feijten (2011) A longitudinal analysis of moving desires, expectations and actual moving behaviour. Environment and Planning A 43.11, 27422760.

Crowder, K., J. Pais and S.J. South (2012) Neighborhood diversity, metropolitan constraints, and household migration. American Sociological Review 77.3, 325-353.

Finney, N., G. Catney and D. Phillips (2015) Ethnicity and internal migration. In D.P. Smith, N. Finney, K. Halfacree and N. Walford (eds), Internal Migration: Geographical Perspectives and Processes, Ashgate, Farnham.

Finney, N. and L. Simpson (2009) 'Sleepwalking to Segregation'? Challenging Myths about Race and Migration. The Policy Press, Bristol. 
Hedman, L., M. van Ham and D. Manley (2011) Neighbourhood choice and neighbourhood reproduction. Environment and Planning A 43.6, 1381-1399.

Imbroscio, D. (2012) Beyond mobility: The limits of Liberal Urban Policy. Journal of Urban Affairs 34.1, 1-20.

loannides, Y. and J. Zabel (2008) Interactions, neighborhood selection and housing demand. Journal of Urban Economics 63.1, 229-252.

Jivraj, S. and O. Khan (2015) How likely are people from minority ethnic groups to live in deprived neighbourhoods? In S. Jivraj and L. Simpson (eds), Ethnic Identity and Inequalities in Britain: The Dynamics of Diversity, Bristol: Policy Press.

Johnston, R., J. Forrest and M. Poulsen (2002) Are there ethnic enclaves/ghettos in English cities? Urban Studies 39.4, 591-618.

Johnston, R., M. Poulsen and J. Forrest (2010) Moving on from indices, refocusing on mix: On measuring and understanding ethnic patterns of residential segregation. Journal of Ethnic and Migration Studies 36.4, 697-706.

Kaufmann, E. and G. Harris (2015) "White Flight" or positive contact? Local diversity and attitudes to immigration in Britain. Comparative Political Studies 48.12, 1563-1590. 
Knies, G. (2017) Understanding Society: The UK Household Longitudinal Study Waves 1-7 User Guide. Institute for Social and Economic Research, University of Essex, Colchester.

Norman, P., P. Boyle and P. Rees (2005) Selective migration, health and deprivation: A longitudinal analysis. Social Science \& Medicine 60, 2755-2771.

Office for National Statistics (ONS) (2012a) Ethnicity and National Identity in England and Wales 2011. Office for National Statistics. [WWW document]. URL http://www.ons.gov.uk/peoplepopulationandcommunity/culturalidentity/ethnicity/articles/ ethnicityandnationalidentityinenglandandwales/2012-12-11 (accessed 09 April 2018).

ONS (2012b) Changes to Output Areas and Super Output Areas in England and Wales, 2001 to 2011. Office for National Statistics. [WWW document]. URL https://www.ons.gov.uk/methodology/geography/ukgeographies/censusgeography (accessed 09 April 2018).

Pais, J., S.J. South and K. Crowder (2012) Metropolitan heterogeneity and minority neighborhood attainment: Spatial assimilation or place stratification? Social Problems 59.2, 258-281.

Peach, C. (1996) Good segregation, bad segregation. Planning Perspectives 11.4, 379398. 
Peach, C. (2009). Slippery segregation: Discovering or manufacturing ghettos? Journal of Ethnic and Migration Studies 35.9, 1381-1395.

Phillips, D. (2006) Parallel lives? Challenging discourses of British Muslim selfsegregation. Environment and Planning D: Society and Space 24.1, 25-40.

Phillips, D. and M. Harrison (2010) Constructing an integrated society: Historical lessons for tackling Black and minority ethnic housing segregation in Britain. Housing Studies 25.2, 221-235.

Poulsen, M., R. Johnston and J. Forrest (2011) Using local statistics and neighbourhood classifications to portray ethnic residential segregation: A London example. Environment and Planning B 38.4, 636-658.

Rabe, B. and M. Taylor (2010) Residential mobility, quality of neighbourhood and life course events. Journal of the Royal Statistical Society: Series A 173.3, 531-555.

Rees, P. and F. Butt (2004) Ethnic change and diversity in England, 1981 - 2001. Area $36.2,174-186$. 
Rees P., P. Wohland and P. Norman (2013) The demographic drivers of future ethnic group populations for UK local areas 2001-2051. The Geographical Journal 179.1, 4460.

Robinson, D. (2005) The search for community cohesion: Key themes and dominant concepts of the public policy agenda. Urban Studies 42.8, 1411-1427.

Schelling, T.C. (1971) Dynamic models of segregation. Journal of Mathematical Sociology 1.2, 143-186.

Simpson, L. (2007) Ghettos of the mind: The empirical behaviour of indices of segregation and diversity. Journal of the Royal Statistical Society Series A 170.2, 405-424.

Simpson, L. and N. Finney (2009) Spatial patterns of internal migration: Evidence for ethnic groups in Britain. Population, Space and Place 15.1, 37-56.

Simpson, L., K. Purdam, A. Tajar, J. Pritchard and D. Dorling (2009) "Jobs deficits, neighbourhood effects, and ethnic penalties: The geography of ethnic-labour-market inequality. Environment and Planning A 41.4, 946-963.

South, S.J., K. Crowder and J. Pais (2008) Inter-neighborhood migration and spatial assimilation in a multiethnic world: Comparing Latinos, Blacks, and Anglos. Social Forces $87.1,415-443$. 
Stillwell, J. and M. Thomas (2016) How far do internal migrants really move? Demonstrating a new method for the estimation of intra-zonal distance. Regional Studies, Regional Science 3.1, 28-47.

Sturgis, P., I. Brunton-Smith, J. Kuha, and J. Jackson. (2014) Ethnic diversity, segregation and the social cohesion of neighbourhoods in London. Ethnic and Racial Studies 37.8, $1286-1309$.

University of Essex. Institute for Social and Economic Research, NatCen Social Research, Kantar Public. (2017). Understanding Society: Waves 1-7, 2009-2016 and Harmonised BHPS: Waves 1-18, 1991-2009. [data collection]. 9th Edition. UK Data Service. SN: 6614

van Ham, M. and P. Feijten (2008) Who wants to leave the neighbourhood? The effect of being different from the neighbourhood population on wishes to move. Environment and Planning A 40.5, 1151-1170. 
Table 1. Descriptive statistics: Stayers

\begin{tabular}{|c|c|c|c|c|c|}
\hline Variable mean (lagged to $t-1$ ) & All & White British & Other White & Asian & Black \\
\hline \multicolumn{6}{|l|}{ 1. Individual and household } \\
\hline Age & 50.69 & 51.87 & 44.17 & 39.53 & 44.17 \\
\hline Female & 0.56 & 0.56 & 0.58 & 0.50 & 0.66 \\
\hline \multicolumn{6}{|l|}{ Partnership status } \\
\hline single & 0.40 & 0.40 & 0.41 & 0.34 & 0.62 \\
\hline cohabiting & 0.11 & 0.12 & 0.11 & 0.02 & 0.09 \\
\hline married & 0.49 & 0.48 & 0.48 & 0.64 & 0.29 \\
\hline Lives with own children aged 0-15 & 0.27 & 0.25 & 0.38 & 0.46 & 0.45 \\
\hline \multicolumn{6}{|l|}{ Highest qualification } \\
\hline higher degree & 0.35 & 0.33 & 0.53 & 0.45 & 0.44 \\
\hline A-Level or equivalent & 0.17 & 0.17 & 0.15 & 0.18 & 0.16 \\
\hline GCSE or equivalent & 0.20 & 0.21 & 0.09 & 0.16 & 0.17 \\
\hline Other & 0.12 & 0.12 & 0.14 & 0.06 & 0.09 \\
\hline None & 0.16 & 0.17 & 0.09 & 0.14 & 0.14 \\
\hline \multicolumn{6}{|l|}{ Employment status } \\
\hline employed & 0.56 & 0.55 & 0.67 & 0.58 & 0.52 \\
\hline unemployed & 0.04 & 0.03 & 0.05 & 0.06 & 0.07 \\
\hline student & 0.02 & 0.02 & 0.02 & 0.08 & 0.08 \\
\hline out of labour force & 0.38 & 0.40 & 0.26 & 0.28 & 0.33 \\
\hline Real monthly household income & 3576.30 & 3552.43 & 4114.98 & 3817.97 & 3074.23 \\
\hline Equivalised household income & 2089.07 & 2104.73 & 2462.80 & 1769.33 & 1704.59 \\
\hline \multicolumn{6}{|l|}{ Housing tenure } \\
\hline owner-occupation & 0.70 & 0.73 & 0.51 & 0.67 & 0.33 \\
\hline social tenancy & 0.18 & 0.18 & 0.17 & 0.14 & 0.53 \\
\hline private tenancy & 0.11 & 0.10 & 0.32 & 0.19 & 0.14 \\
\hline \multicolumn{6}{|l|}{ 2. Neighbourhood } \\
\hline$\%$ White British & 82.70 & 86.56 & 69.69 & 47.62 & 46.07 \\
\hline Carstairs score (high=more deprived) & -0.02 & -0.29 & 0.42 & 2.36 & 3.41 \\
\hline Population density & 39.20 & 34.80 & 57.73 & 72.36 & 90.36 \\
\hline \multicolumn{6}{|l|}{ 3. Local Authority District } \\
\hline$\%$ White British & 82.03 & 84.77 & 69.86 & 60.56 & 52.75 \\
\hline$\%$ LSOAs in most deprived quintile & 18.97 & 17.23 & 23.01 & 33.84 & 40.01 \\
\hline Population density & 19.33 & 16.33 & 35.60 & 38.50 & 56.80 \\
\hline Unweighted base (person-years) & 55051 & 46158 & 1647 & 4601 & 2645 \\
\hline
\end{tabular}

Notes: Incomes adjusted to January 2015 prices and equivalised using the Modified OECD scale. 
Table 2. Descriptive statistics: Movers

\begin{tabular}{|c|c|c|c|c|c|}
\hline Variable mean (lagged to $t-1$ ) & All & White British & Other White & Asian & Black \\
\hline \multicolumn{6}{|l|}{ 1. Individual and household } \\
\hline Age & 36.33 & 36.92 & 34.59 & 32.50 & 33.15 \\
\hline Female & 0.54 & 0.55 & 0.57 & 0.41 & 0.57 \\
\hline \multicolumn{6}{|l|}{ Partnership status } \\
\hline single & 0.50 & 0.52 & 0.37 & 0.39 & 0.60 \\
\hline cohabiting & 0.19 & 0.21 & 0.19 & 0.04 & 0.08 \\
\hline married & 0.30 & 0.27 & 0.45 & 0.56 & 0.32 \\
\hline Lives with own children aged 0-15 & 0.31 & 0.29 & 0.43 & 0.40 & 0.46 \\
\hline \multicolumn{6}{|l|}{ Highest qualification } \\
\hline higher degree & 0.42 & 0.40 & 0.43 & 0.67 & 0.45 \\
\hline A-Level or equivalent & 0.23 & 0.24 & 0.18 & 0.16 & 0.24 \\
\hline GCSE or equivalent & 0.20 & 0.22 & 0.11 & 0.07 & 0.14 \\
\hline other & 0.08 & 0.07 & 0.21 & 0.05 & 0.06 \\
\hline none & 0.07 & 0.08 & 0.06 & 0.05 & 0.11 \\
\hline \multicolumn{6}{|l|}{ Employment status } \\
\hline employed & 0.64 & 0.64 & 0.75 & 0.68 & 0.46 \\
\hline unemployed & 0.06 & 0.06 & 0.06 & 0.06 & 0.11 \\
\hline student & 0.08 & 0.08 & 0.03 & 0.08 & 0.20 \\
\hline out of labour force & 0.22 & 0.23 & 0.16 & 0.17 & 0.23 \\
\hline Real monthly household income & 3748.56 & 3749.37 & 4062.66 & 3759.00 & 3150.12 \\
\hline Equivalised household income & 2183.52 & 2198.68 & 2451.01 & 2040.82 & 1648.37 \\
\hline \multicolumn{6}{|l|}{ Housing tenure } \\
\hline owner-occupation & 0.39 & 0.43 & 0.19 & 0.25 & 0.13 \\
\hline social tenancy & 0.16 & 0.17 & 0.11 & 0.08 & 0.30 \\
\hline private tenancy & 0.44 & 0.40 & 0.70 & 0.67 & 0.57 \\
\hline Moved Local Authority District & 0.38 & 0.37 & 0.41 & 0.47 & 0.39 \\
\hline \multicolumn{6}{|l|}{ 2. Neighbourhood } \\
\hline$\%$ White British ( $t-1)$ & 79.02 & 83.92 & 60.43 & 47.68 & 57.80 \\
\hline$\%$ White British $(t)$ & 80.79 & 85.00 & 67.91 & 52.25 & 60.70 \\
\hline Carstairs score $(t-1)$ & 0.35 & 0.09 & 0.92 & 2.17 & 2.09 \\
\hline Carstairs score $(t)$ & 0.03 & -0.18 & 0.37 & 1.40 & 1.84 \\
\hline Population density $(t-1)$ & 48.21 & 43.33 & 67.18 & 75.11 & 78.39 \\
\hline Population density $(t)$ & 44.35 & 40.22 & 59.37 & 68.37 & 68.76 \\
\hline \multicolumn{6}{|l|}{ 3. Local Authority District } \\
\hline$\%$ White British $(t-1)$ & 79.66 & 83.54 & 64.64 & 54.86 & 63.30 \\
\hline$\%$ White British $(t)$ & 80.58 & 84.06 & 69.93 & 56.70 & 64.82 \\
\hline$\%$ LSOAs in most deprived quintile $(t-1)$ & 20.12 & 18.03 & 24.75 & 34.42 & 33.01 \\
\hline$\%$ LSOAs in most deprived quintile $(t)$ & 19.12 & 17.42 & 20.56 & 31.61 & 31.73 \\
\hline Population density $(t-1)$ & 22.67 & 18.72 & 39.72 & 45.76 & 41.07 \\
\hline Population density $(t)$ & 21.09 & 17.83 & 31.35 & 42.54 & 37.58 \\
\hline Unweighted base (person-years) & 3180 & 2546 & 144 & 333 & 157 \\
\hline
\end{tabular}

Notes: Incomes adjusted to January 2015 prices and equivalised using the Modified OECD scale. 
Table 3. Linear regression models of destination LSOA characteristics

\begin{tabular}{|c|c|c|c|c|c|c|c|c|}
\hline \multirow{3}{*}{$\begin{array}{l}\text { Variable (lagged to } t-1 \text { ) } \\
\text { Ethnicity (ref=White British) }\end{array}$} & \multicolumn{4}{|c|}{ Model 1: \% White British } & \multicolumn{4}{|c|}{ Model 2: Carstairs score } \\
\hline & \multirow{2}{*}{ Coefficient } & \multirow[t]{2}{*}{ Std. Err. } & \multicolumn{2}{|c|}{$[95 \% \mathrm{Cl}]$} & \multirow{2}{*}{ Coefficient } & \multirow[t]{2}{*}{ Std. Err. } & \multicolumn{2}{|c|}{$[95 \% \mathrm{Cl}]$} \\
\hline & & & & & & & & \\
\hline Other White & $-4.934^{\star *}$ & 1.864 & {$[-8.601$} & $-1.267]$ & 0.358 & 0.218 & {$[-0.071$} & $0.786]$ \\
\hline Asian & $-13.997^{\star * *}$ & 2.192 & {$[-18.309$} & $-9.686]$ & $1.201^{* * *}$ & 0.248 & {$[0.714$} & 1.689] \\
\hline Black & $-11.707^{\star * \star}$ & 2.348 & {$[-16.326$} & $-7.088]$ & $1.097^{*}$ & 0.529 & {$[0.057$} & $2.138]$ \\
\hline Ln equivalised household income & -0.325 & 0.476 & {$[-1.261$} & $0.612]$ & $-0.308^{* *}$ & 0.096 & {$[-0.496$} & $-0.120]$ \\
\hline Other White \# In income & 1.656 & 1.072 & {$[-0.454$} & $3.765]$ & $0.382^{*}$ & 0.164 & {$[0.059$} & $0.706]$ \\
\hline Asian \# In income & $4.112^{* *}$ & 1.583 & {$[0.999$} & $7.226]$ & -0.205 & 0.205 & {$[-0.607$} & $0.198]$ \\
\hline Black \# In income & -1.444 & 1.954 & {$[-5.287$} & 2.399] & 0.062 & 0.248 & {$[-0.425$} & $0.550]$ \\
\hline Age & $0.136^{\star * *}$ & 0.026 & {$[0.085$} & $0.186]$ & $-0.019^{* * *}$ & 0.005 & {$[-0.028$} & $-0.010]$ \\
\hline Female $($ ref $=$ male $)$ & -0.024 & 0.627 & {$[-1.256$} & $1.209]$ & -0.151 & 0.107 & {$[-0.361$} & 0.059] \\
\hline \multicolumn{9}{|l|}{ Partnership status (ref=single) } \\
\hline cohabiting & 1.816 & 0.937 & {$[-0.027$} & 3.659] & -0.038 & 0.158 & {$[-0.349$} & $0.274]$ \\
\hline married & $2.328^{* *}$ & 0.737 & {$[0.879$} & $3.778]$ & $-0.530^{* * *}$ & 0.136 & {$[-0.798$} & $-0.263]$ \\
\hline Lives with own children (ref=no) & $3.350^{* * *}$ & 0.693 & {$[1.986$} & $4.714]$ & -0.136 & 0.132 & {$[-0.396$} & $0.124]$ \\
\hline \multicolumn{9}{|l|}{ Highest qualification (ref= higher degree) } \\
\hline A-Level & $2.283^{*}$ & 0.892 & {$[0.528$} & 4.039] & 0.178 & 0.165 & {$[-0.147$} & $0.503]$ \\
\hline GCSE & 0.623 & 0.945 & {$[-1.236$} & 2.482] & $0.835^{\star * *}$ & 0.167 & {$[0.506$} & 1.164] \\
\hline other & -0.113 & 1.275 & {$[-2.621$} & 2.395] & $0.789^{* * *}$ & 0.221 & {$[0.355$} & 1.223] \\
\hline none & 1.019 & 1.581 & {$[-2.091$} & 4.129] & $0.821^{* *}$ & 0.254 & {$[0.323$} & 1.320] \\
\hline \multicolumn{9}{|l|}{ Employment status (ref=employed) } \\
\hline unemployed & -2.487 & 1.805 & {$[-6.038$} & $1.063]$ & $0.713^{* *}$ & 0.258 & {$[0.207$} & 1.220] \\
\hline student & -2.502 & 1.440 & {$[-5.335$} & $0.330]$ & $-0.678^{* *}$ & 0.260 & {$[-1.189$} & $-0.166]$ \\
\hline inactive & -1.438 & 0.938 & {$[-3.283$} & $0.407]$ & $0.468^{* *}$ & 0.178 & {$[0.117$} & $0.818]$ \\
\hline \multicolumn{9}{|l|}{ Housing tenure (ref=private tenancy) } \\
\hline owner-occupation & 0.299 & 0.664 & {$[-1.006$} & 1.605] & $-0.386^{\star *}$ & 0.129 & {$[-0.640$} & $-0.131]$ \\
\hline social tenancy & -1.316 & 0.951 & {$[-3.186$} & $0.554]$ & $1.013^{\star * *}$ & 0.201 & {$[0.617$} & $1.408]$ \\
\hline Moved district $(\mathrm{ref}=\mathrm{no})$ & 1.879 & 1.003 & {$[-0.095$} & 3.853] & $-0.568^{\star * *}$ & 0.136 & {$[-0.836$} & $-0.300]$ \\
\hline$\%$ White British in district & $0.727^{\star \star \star}$ & 0.032 & {$[0.664$} & $0.791]$ & 0.006 & 0.006 & {$[-0.005$} & $0.017]$ \\
\hline$\%$ of district LSOAs in most deprived quintile & $0.141^{\star * \star}$ & 0.032 & {$[0.077$} & $0.204]$ & $0.051^{* * *}$ & 0.005 & {$[0.041$} & $0.061]$ \\
\hline Constant & $79.733^{* * *}$ & 1.050 & {$[77.669$} & 81.798] & -0.038 & 0.185 & {$[-0.402$} & $0.325]$ \\
\hline Model $r^{2}$ & 0.548 & & & & 0.285 & & & \\
\hline Unweighted $n$ moves & 3180 & & & & 3180 & & & \\
\hline
\end{tabular}


Figure 1. Predicted percent White British in destination LSOA by ethnicity and household income
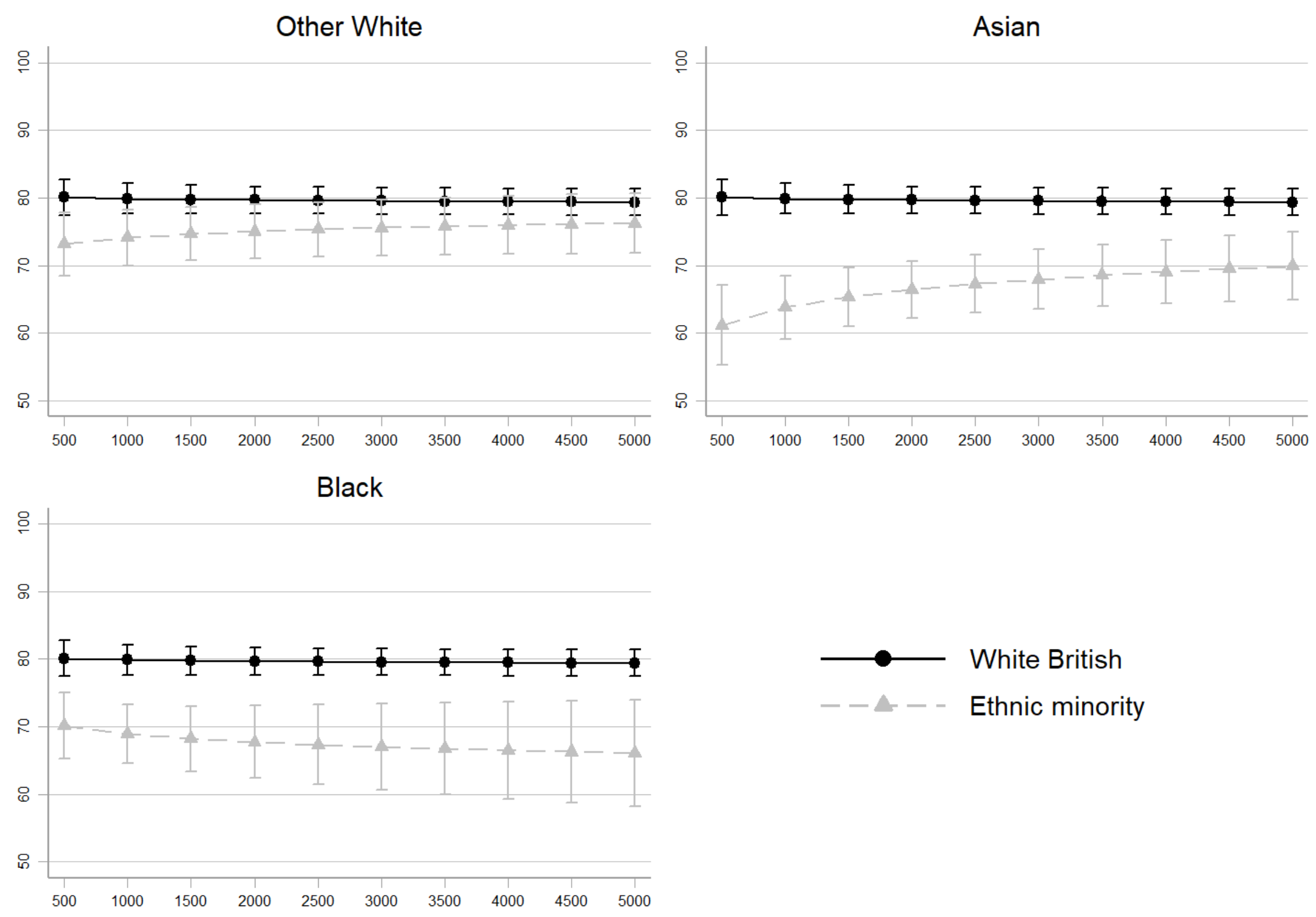

Notes: Predicted \% White British on y axes, household income on $\mathrm{x}$ axes. 95\% Cls. 
Figure 2. Predicted Carstairs score of destination LSOA by ethnicity and household income
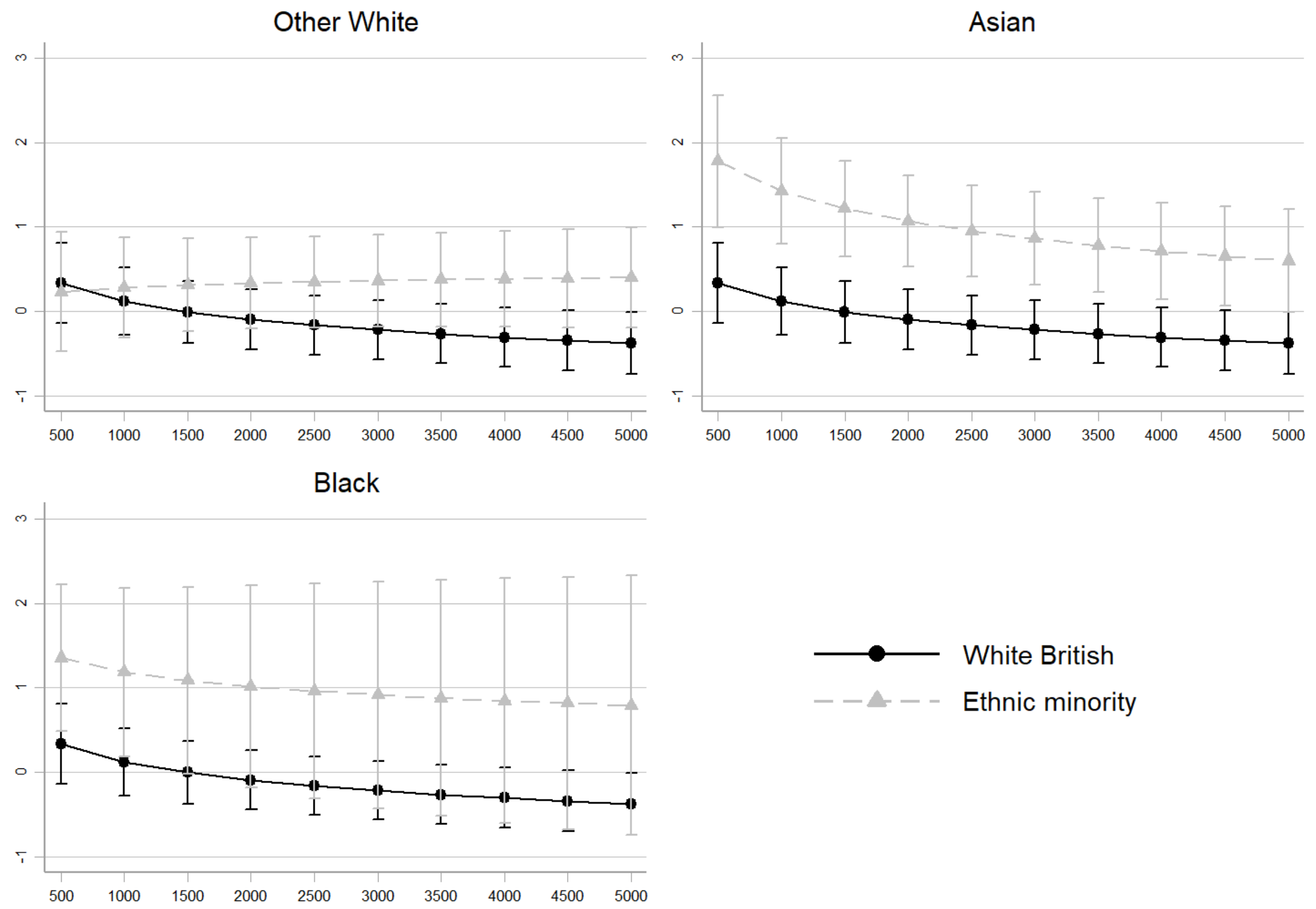

$\longrightarrow$ White British

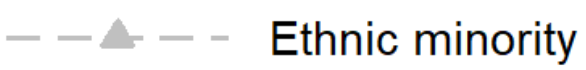

Notes: Predicted Carstairs score on y axes, household income on $\mathrm{x}$ axes. $95 \% \mathrm{Cls}$. 